\title{
Physical Characteristics of Stream Subbasins in the Lac qui Parle River Basin, Southwestern Minnesota and Eastern South Dakota
}

\author{
By D.L. Lorenz, C.A. Sanocki, and T.A. Winterstein
}

\begin{abstract}
Data describing the physical characteristics of stream subbasins upstream from selected points on streams in the Lac qui Parle River Basin, located in southwestern Minnesota and eastern South Dakota, are presented in this report. The physical characteristics are the drainage area of the subbasin, the percentage area of the subbasin covered only by lakes, the percentage area of the subbasin covered by both lakes and wetlands, the main-channel length, and the main-channel slope. The points on the stream include outlets of subbasins of at least 5 square miles, outfalls of sewage treatments plants, and locations of U.S. Geological Survey low-flow, high-flow, and continuous-record gaging stations.
\end{abstract}

\section{Introduction}

This report is one of several that present subbasin characteristics of streams in Minnesota. This report presents selected data for points on streams at outlets of subbasins larger than about 5 square miles; at outfalls of sewage treatment plants; and at locations of U.S.

Geological Survey low-flow, high-flow, and continuousrecord gaging stations located in the Lac qui Parle River Basin.

The Lac qui Parle River drains an area of 1,096 square miles. The Lac qui Parle River Basin is represented by hydrologic accounting unit 07020003 (U.S. Geological Survey, 1974a and 1974b) and includes parts of Lac qui Parle, Yellow Medicine, and Lincoln Counties in southwestern Minnesota and parts of Grant, Deuel, and Brooking Counties in eastern South Dakota.

This report was prepared in cooperation with the Minnesota Department of Transportation and the U.S. Army Corps of Engineers.

\section{Acknowledgments}

The Minnesota State Planning Information Center provided assistance with much of the digitizing and programing needed to produce this report. The Center's assistance is gratefully acknowledged.

\section{Methods}

\section{U.S. Geological Survey 7-1/2 minute series} topographic maps were used as source maps to obtain the data recorded in this report. Paper copies of the maps were used. Data recorded from paper copies were in error by no more than twice the horizontal accuracy of National Mapping Standards of 40 feet (Thompson, 1987, p. 104). Data recorded from these maps were projected into an Albers Equal-Area projection for storage and analysis.

The subbasin boundaries were delineated on the basis of topographic features and human activities recorded on topographic maps. Human activities along subbasin divides such as the installation of storm sewers, the drainage of wetlands, and the diversions of streams may alter the drainage area of the stream. Therefore, data from field inspections and recent drainage-ditch maps were transferred to the topographic maps.

The subbasin boundaries (represented by line segments) and labels were recorded using a geographic information system (GIS). The GIS was used to define the subbasin polygons, recording the line segments that comprise each subbasin and identifying the subbasin with a label. The GIS automatically calculates the area of each subbasin.

The lake data were obtained from the Minnesota State Planning Information Center. The outline of each water body was compared to 7-1/2 minute topographic maps. The lake data were overlaid onto the subbasin data to associate each lake with a subbasin. The total lake area for each subbasin was calculated by the GIS.

Marsh data were recorded using a computer-aided drafting (CAD) system and, transferred to the GIS. The marsh data were overlaid onto the subbasin data to associate each marsh area with a subbasin. The total 
marsh area for each subbasin was calculated by the GIS. The total marsh area plus the lake area is the storage area.

Main channels were delineated for each subbasin on the 7-1/2 minute topographic maps starting at the mouth of the subbasin and working upstream. Whenever the main channel joined with another stream, the stream upstream of the junction that drained the largest area was selected as the main channel. The main channel is continuous and is a single trace that passes through marshes, lakes, and the midline of wide rivers and braided streams. The main channel was extended to the basin divide from the uppermost stream trace on the topographic map. The stream-channel segments forming the main channel were recorded using the CAD and transferred to the GIS. Several computer programs were used to automatically identify the line segments forming an individual stream channel and to enter this information into the GIS data base. These programs also identified the main channel of a stream system that drained more than one subbasin using the rule that the main channel is the stream that drains the largest area.

Elevation data at the intersection of topographic contour lines and main channels were recorded using the CAD system. The data were transferred to the GIS and each data point was associated with a main-channel line segment. Two points on the main channel, at 10 percent and at 85 percent of the main-channel length from the basin outlet to the drainage divide, were located by the GIS. The elevations of these two points were interpolated from the data recorded in the GIS. Main-channel slope was calculated by dividing the difference in elevation between these points by the distance along the main channel between these points.

\section{Physical Characteristics of Stream Subbasins}

The physical characteristics determined for each of the subbasins shown on plate 1 are presented in table 1 at the end of the report. The stream subbasins presented in table 1 are ordered from headwaters to mouth. The rank of the stream is shown by indentation and indicates the drainage pattern of the stream. Rank was assigned by area of the drainage basin drained by the stream. Whenever two streams joined, the stream draining the smaller of the two drainage basins was assigned a lower rank. The firstranked river is the Lac qui Parle River. Tributary streams are indented.

The data for drainage area, for main-channel length, and for main-channel slope are reported using three significant figures or rounded to the nearest hundredth of a unit. The data for lake area and for storage area are reported using two significant figures or to the nearest tenth of a percent.

The following is an explanation of terms used in table 1:

Subbasin Number. The number is based on the Minnesota Common Stream Number System.

Stream Name and Location. The name of the stream shown on U.S. Geological Survey 1:24,000 topographic maps. County and judicial ditch names were verified using county ditch maps prepared by Lac qui Parle, Yellow Medicine, and Lincoln Counties. The relative position of the subbasin above other subbasins, streams, gaging stations, and outfalls from sewage treatment plants also is given.

Outlet Location. The U.S. Public Lands Survey System is used to describe the location of the subbasin outlet down to quarter-quarter section. The description includes quarter-quarter section, section, township, and range.

Drainage Area. That area, measured on a horizontal plane, enclosed by a topographic divide, within which direct surface runoff from precipitation normally flows by gravity into a watercourse above a specific point. This may include closed basins and other areas that do not contribute directly to surface runoff.

Lake Area. The percentage of the drainage area covered by open water.

Storage Area. The percentage of a drainage area covered by open water and marshes as shown on 7-1/2 minute topographic maps. Marsh areas are not shown on plate 1 .

Main-channel Length. The total length of the main channel from the basin outlet to the drainage divide. The main channel is the watercourse that drains the greatest area.

Main-channel Slope. The average slope of the watercourse between the points at 10 and at 85 percent of the distance along the main channel from the basin outlet to the drainage divide.

\section{References Cited}

Thompson, M.M., 1987, Maps for America, Third edition: U.S. Geological Survey, 265 p.

U.S. Geological Survey, 1974a, Hydrologic unit map1974 State of Minnesota: Scale 1:500,000, 1 plate.

U.S. Geological Survey, 1974b, Hydrologic unit map1974 State of South Dakota: Scale 1:500,000, 1 plate. 


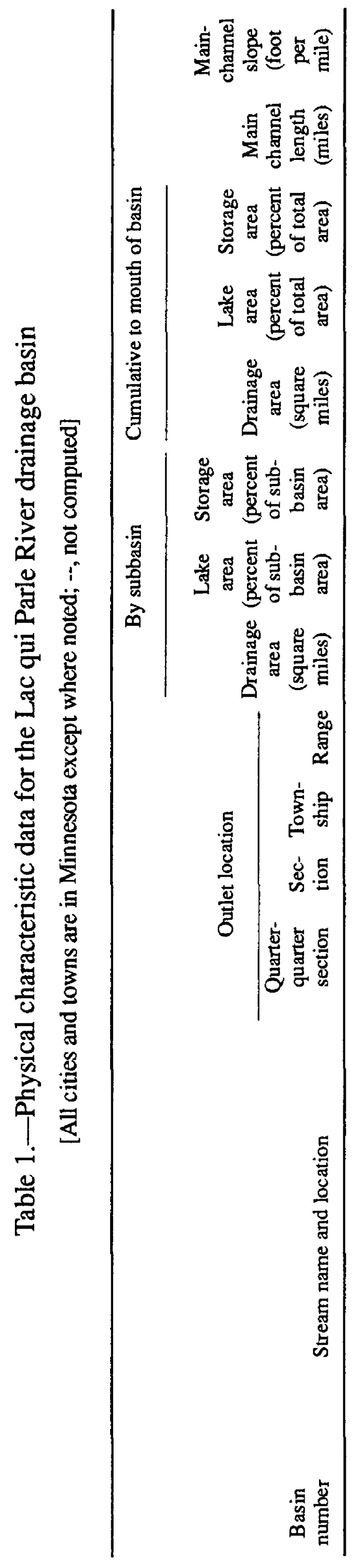

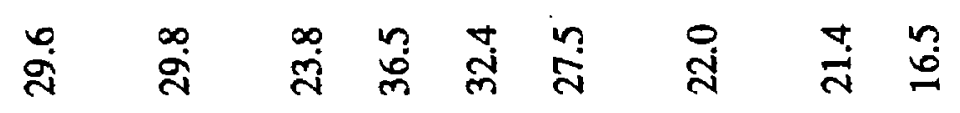

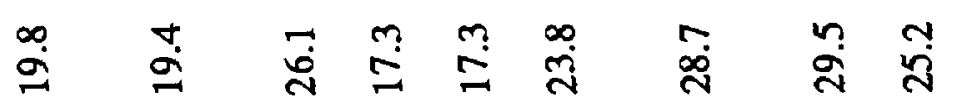

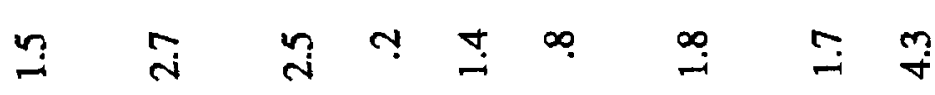

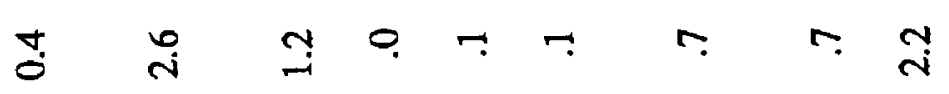

ป

च त

I

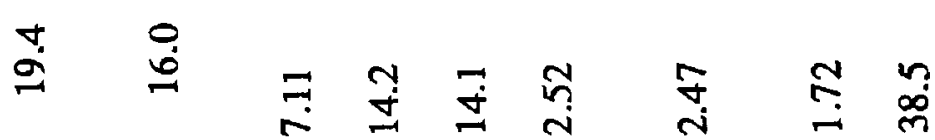

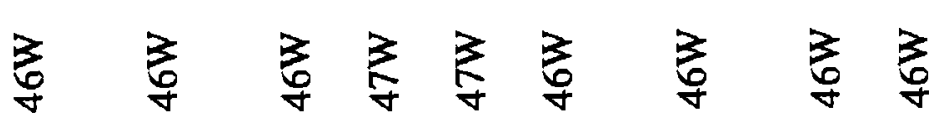

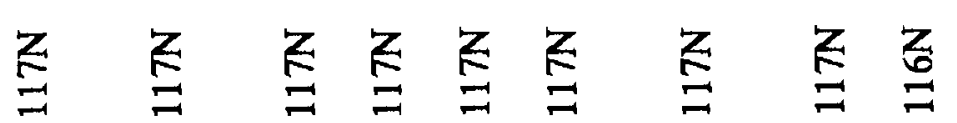

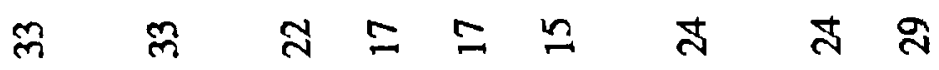

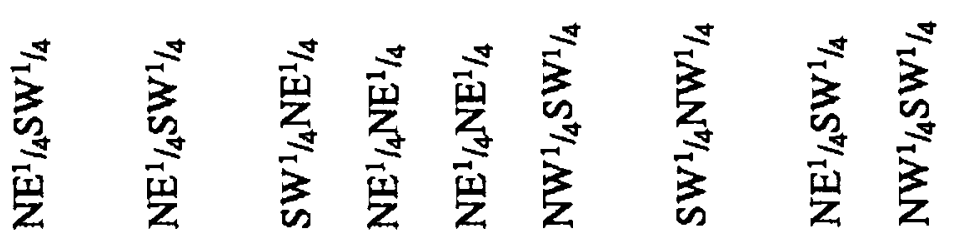

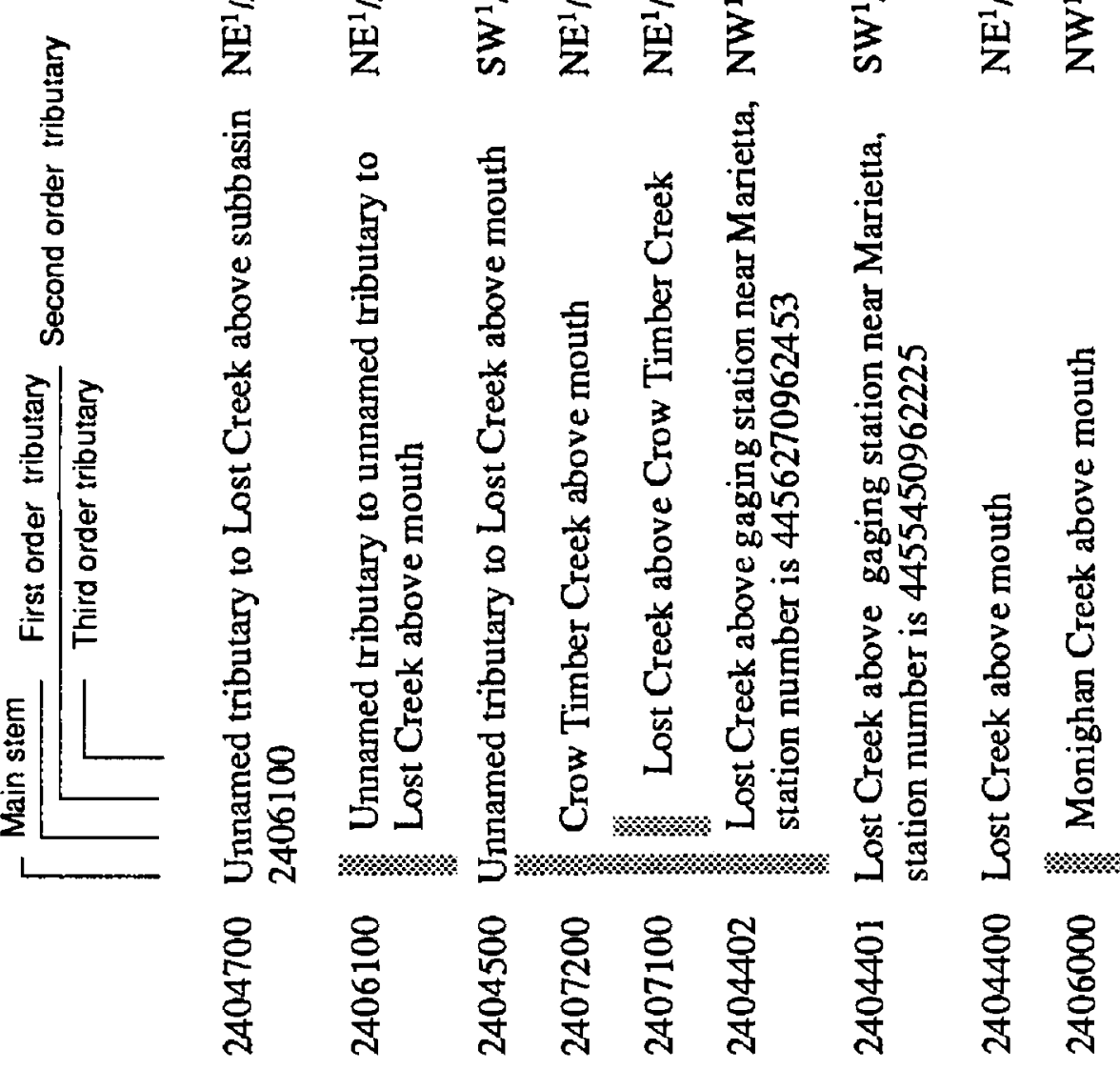




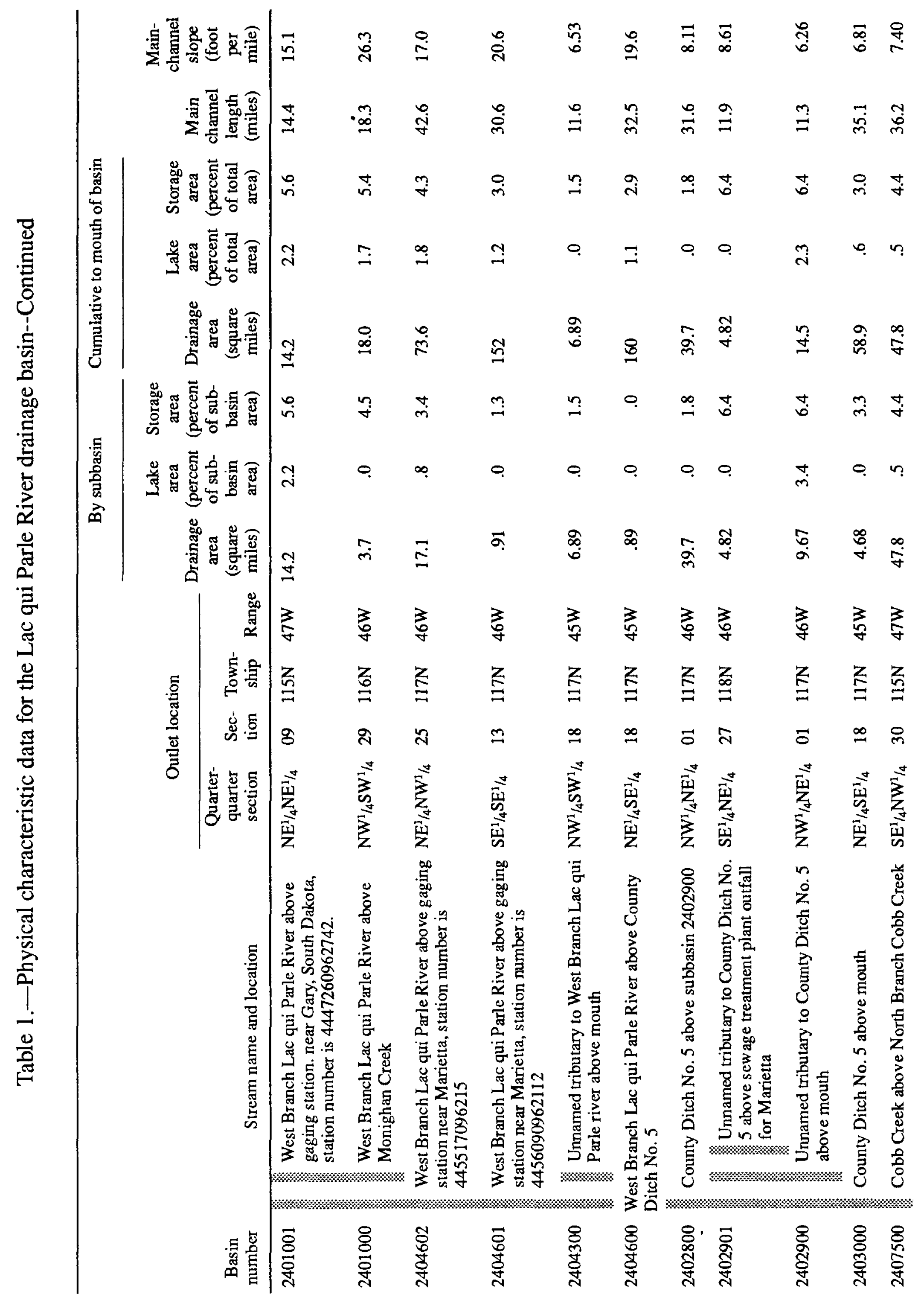




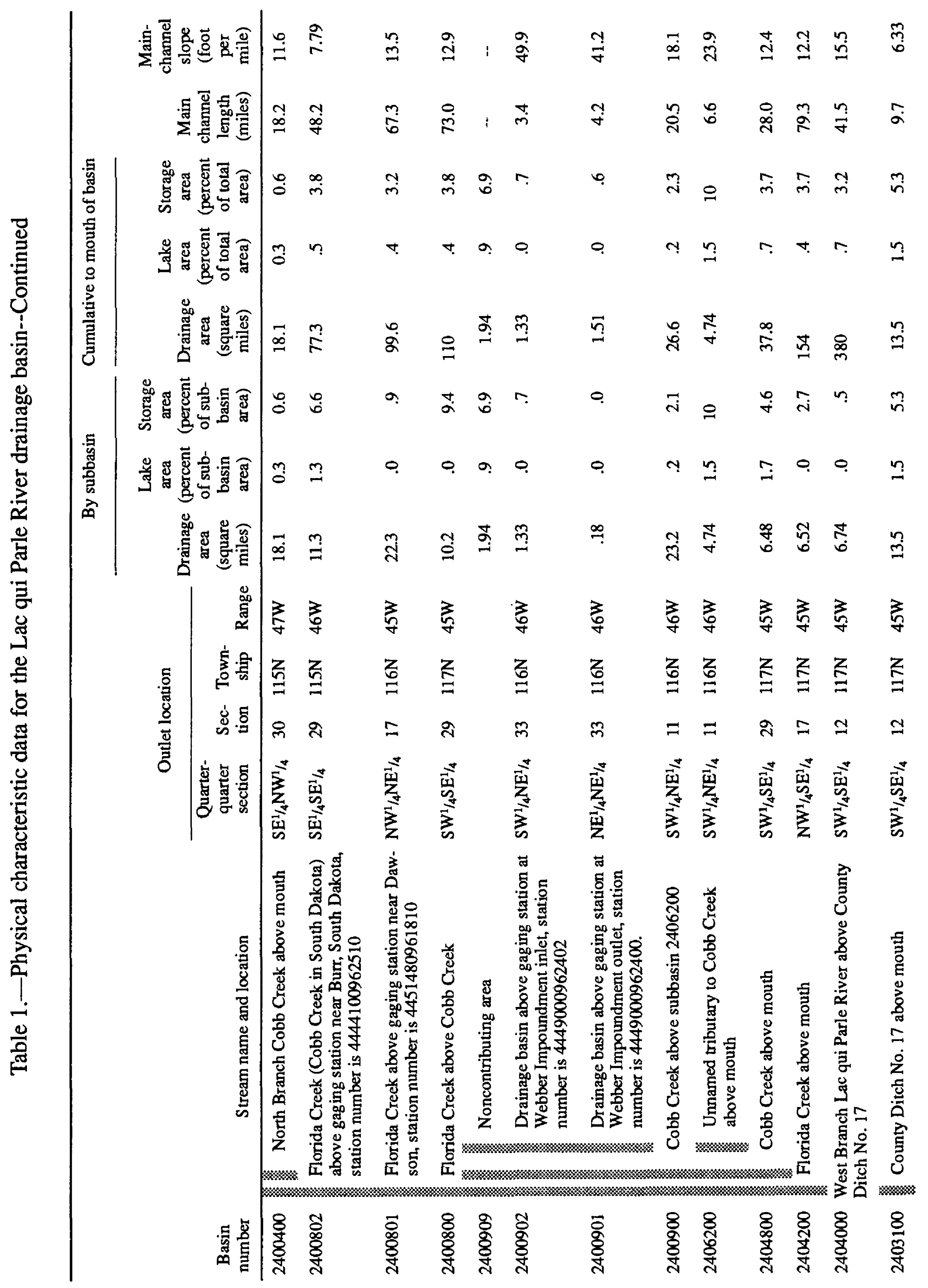




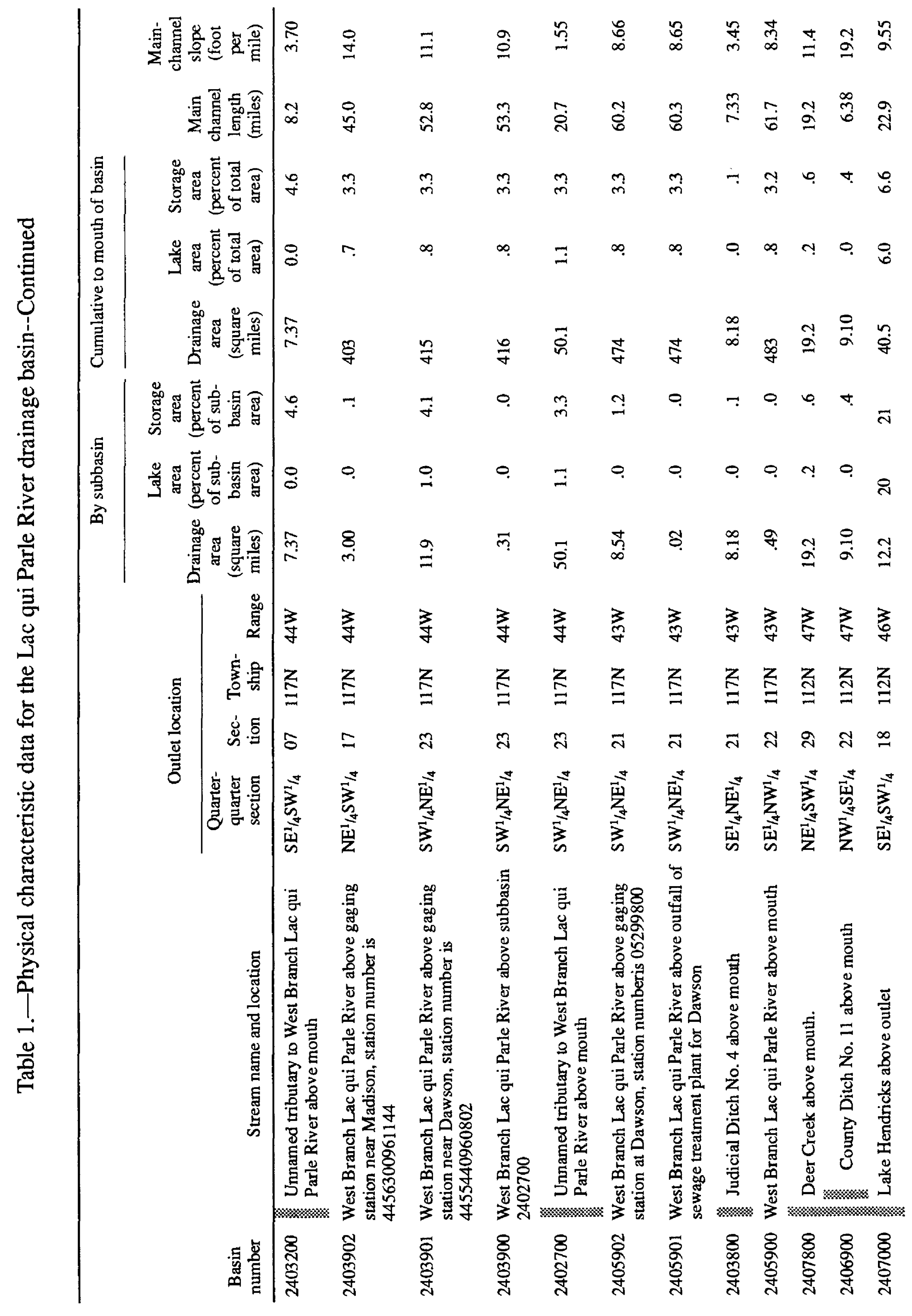




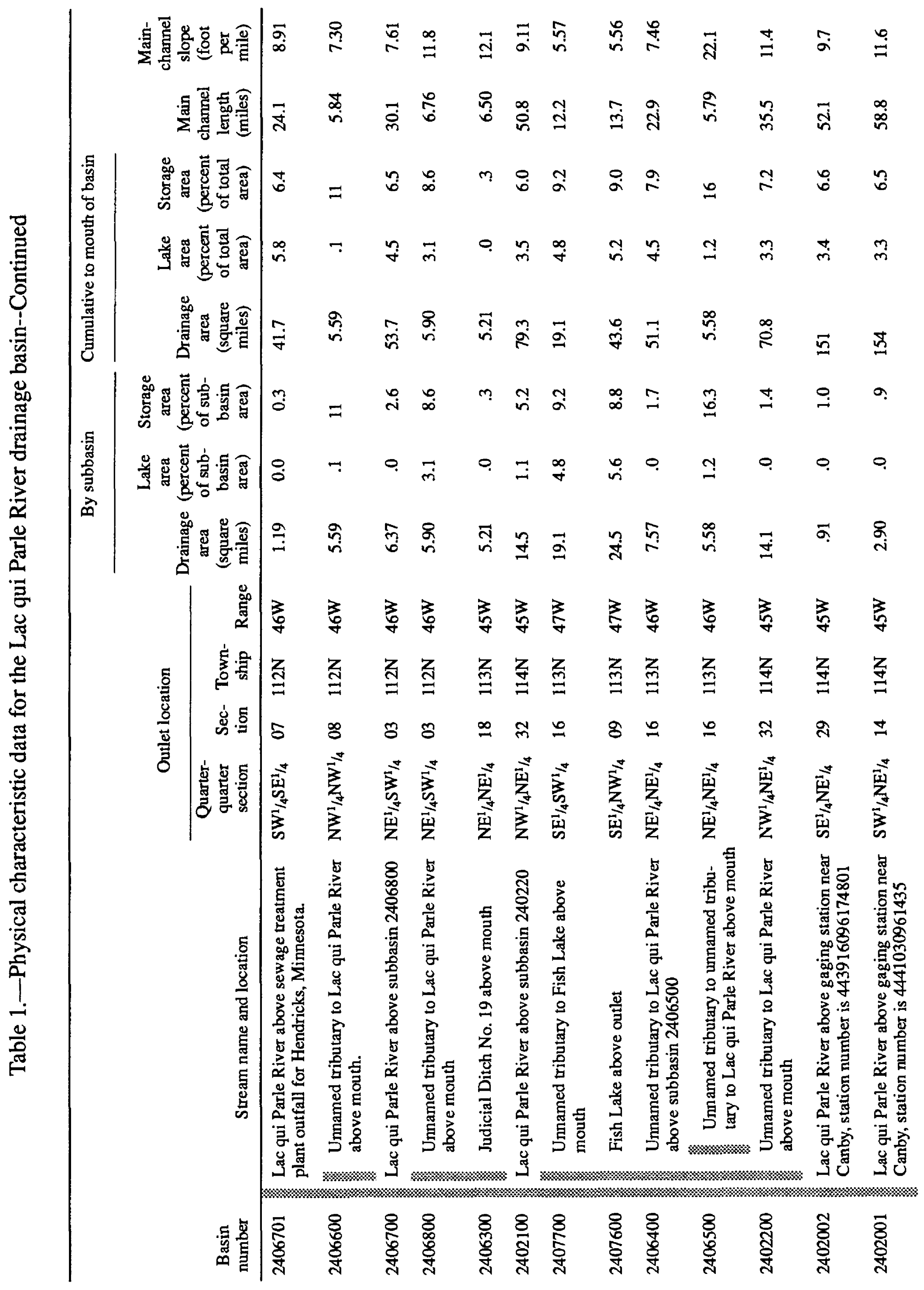




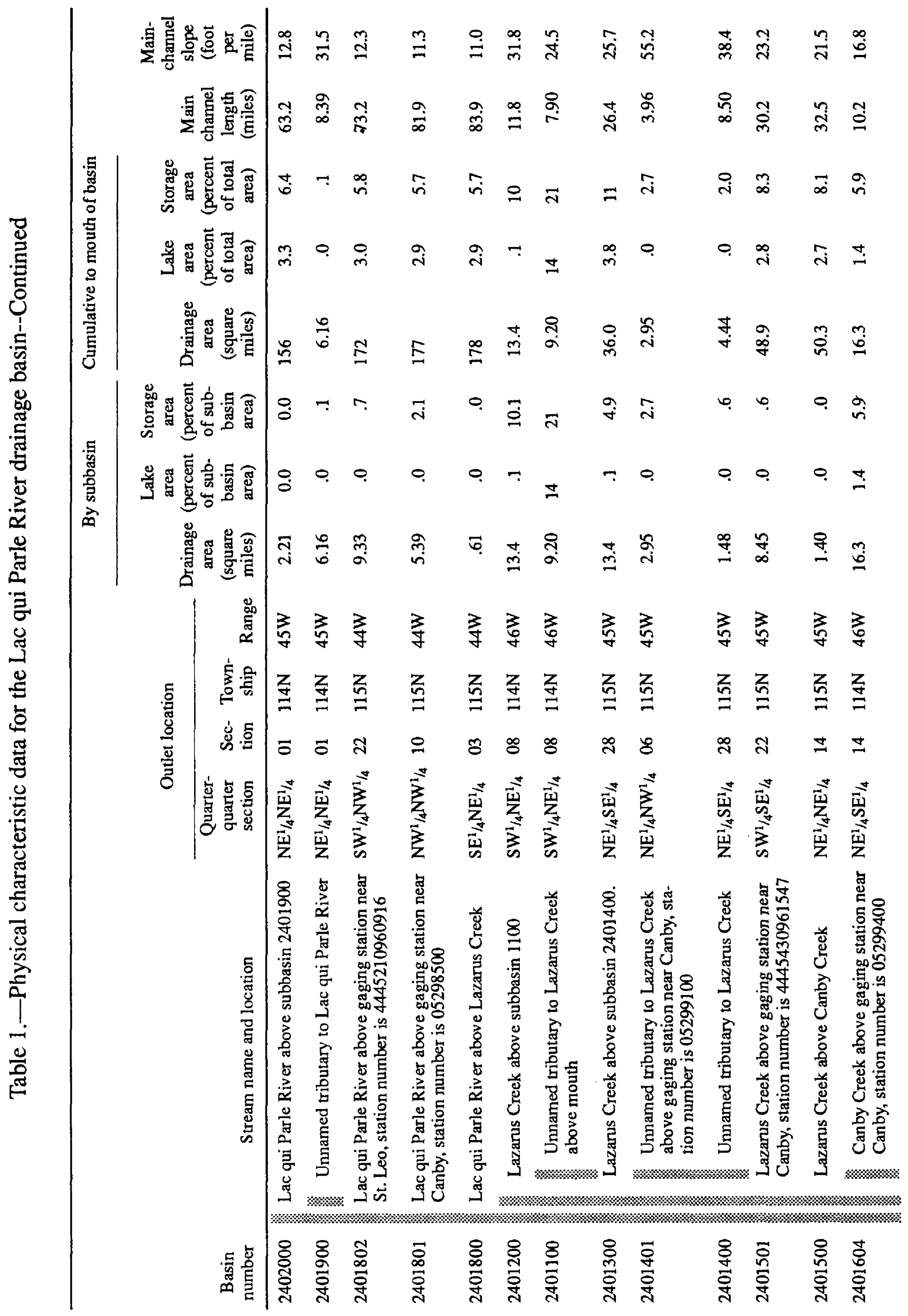




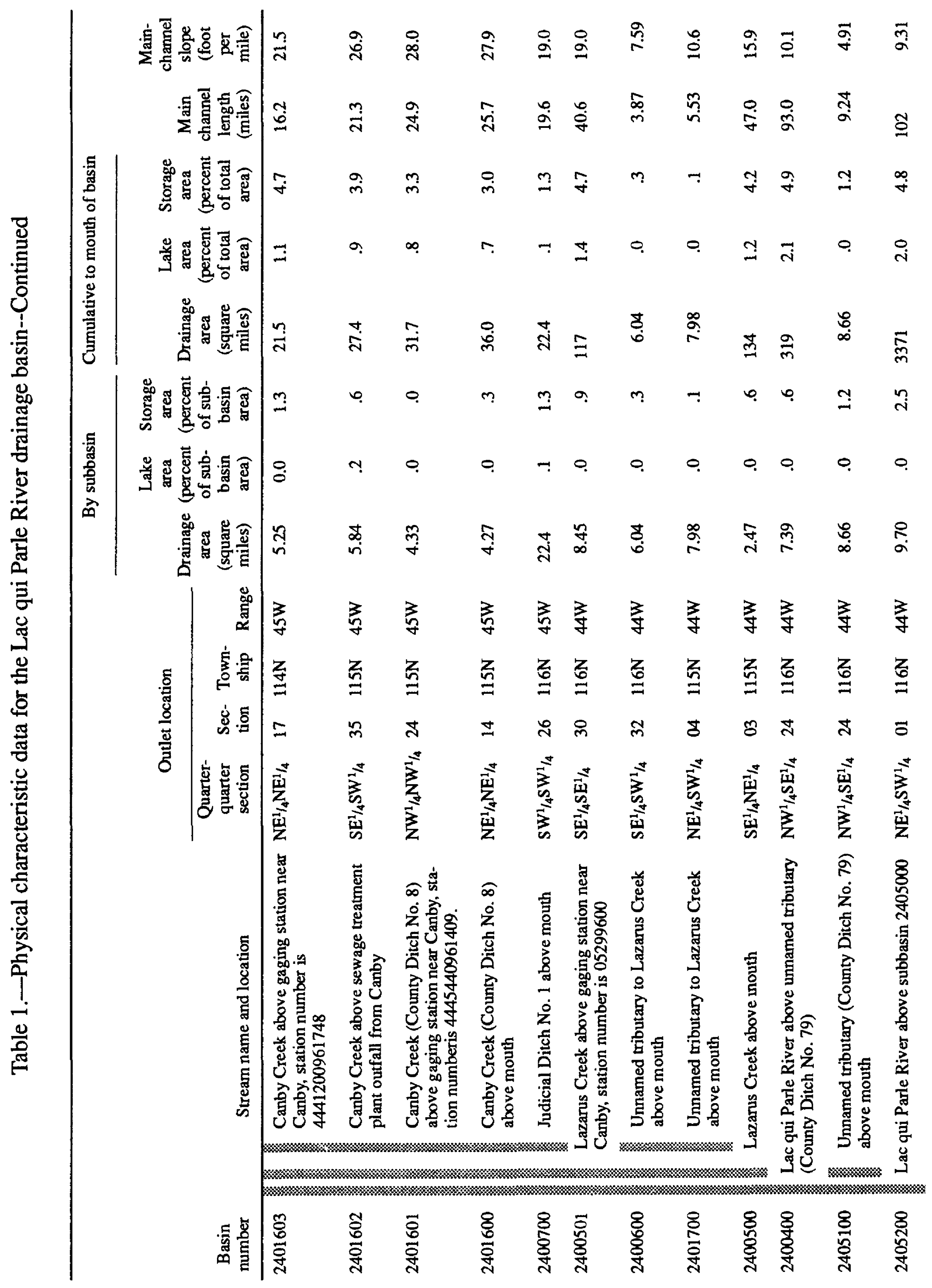




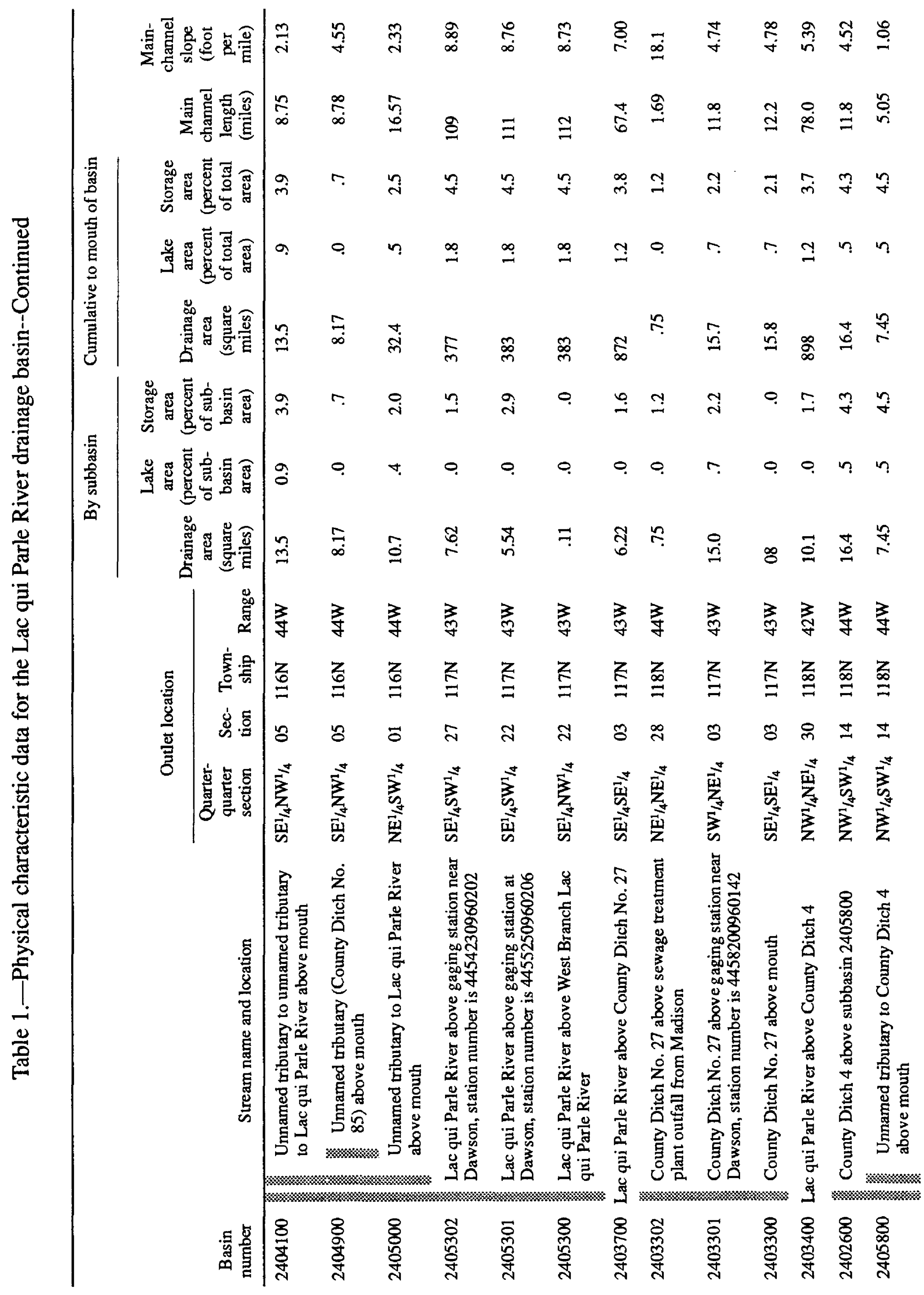




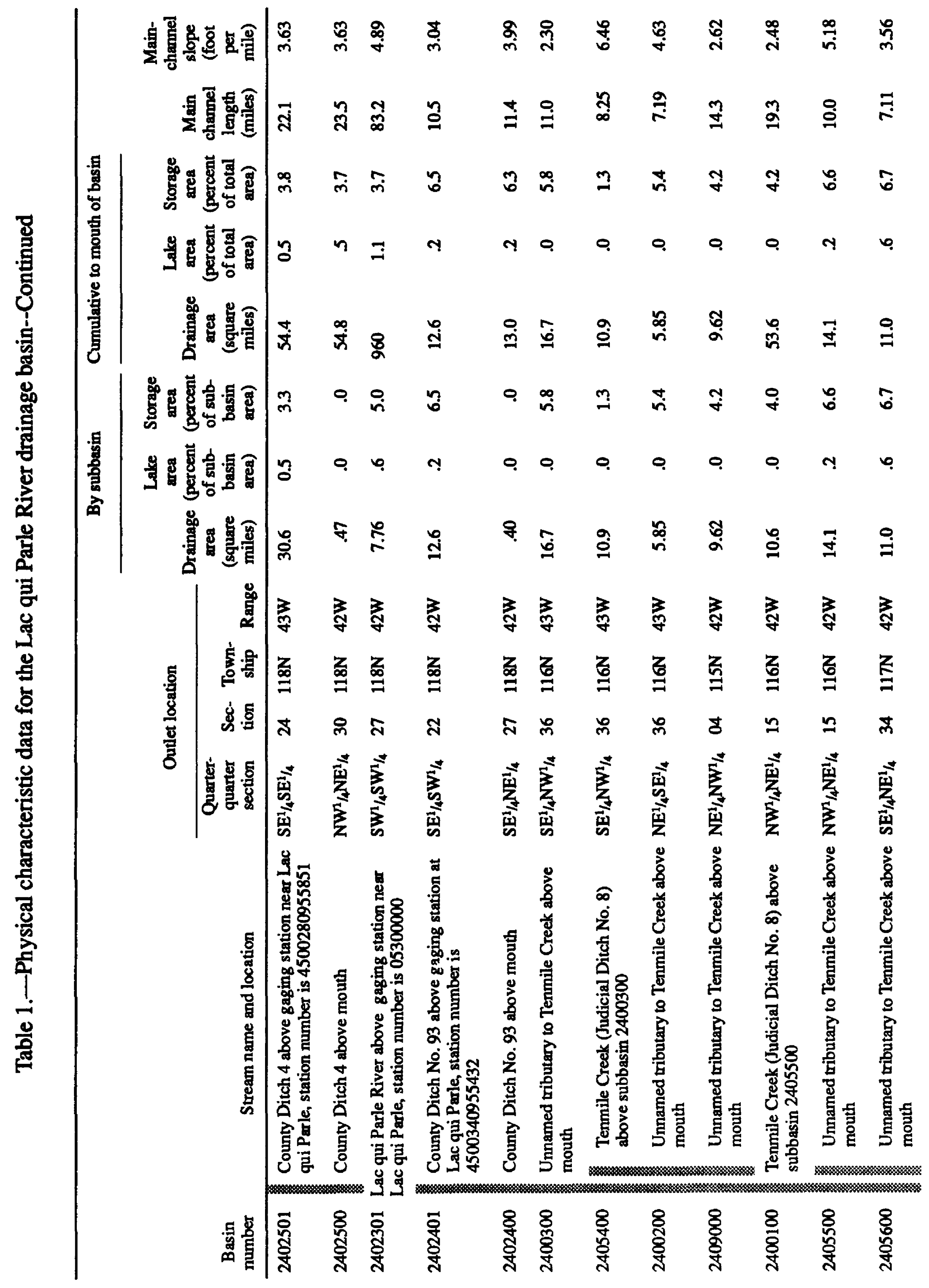




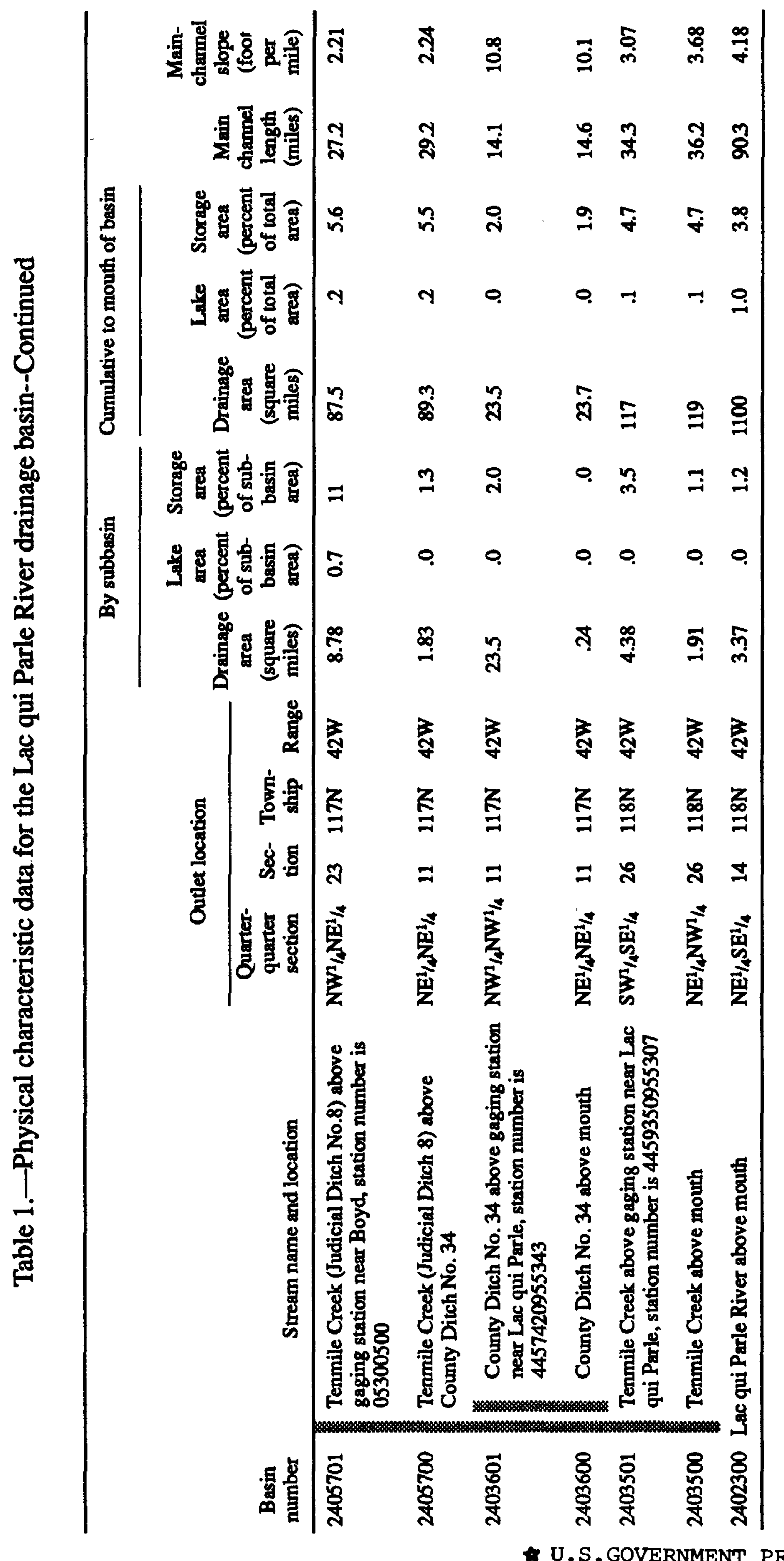

* U.S.GOVERNMENT PRINTING OFFICE:1994 558-212 